\title{
Monetary policy, exchange rates and stock prices in the Middle East region
}

\begin{abstract}
A structural vector autoregressive model is employed to investigate the impact of monetary policy and real exchange rate shocks on the stock market performance of Kuwait, Oman, Saudi Arabia, Egypt and Jordan. In order to identify the structural shocks both short run and long run restrictions are applied. Unlike previous literature the contemporaneous interdependence between the financial variables are left unrestricted to give a more accurate depiction of the relationships. The heterogeneity of the results reflect the different monetary policy frameworks and stock market characteristics of these countries. Mainly, monetary policy and the real exchange rate shocks have a significant short run impact on the stock prices of the countries that apply a relatively more independent monetary policy and flexible exchange rates.
\end{abstract}

JEL classification: C32; E52; G18

Keywords: SVAR, Monetary Policy, Asset Prices, Emerging Financial Market. 


\section{Introduction}

The debate between academics and policy makers regarding whether or not monetary policy should respond to the developments in the financial markets has been ongoing for quite a while with no consensus reached. The main motivation behind this dispute is the potential impact that asset price fluctuations could have on the real economic sector, mainly output and inflation. The 2007 US Subprime crisis and its repercussions throughout the world financial markets, and the spillover effects of the rise and later collapse of asset prices on real economic activity, has only led to the reignition of this debate.

On the one hand, proponents ${ }^{1}$ of a proactive monetary policy response to asset price booms and busts argue that such cycles can be costly, creating distortions in investment and consumption decisions and leading to excessive fluctuations in output and inflation. They propose a policy where monetary authorities "lean against the wind", that is raising and lowering interest rates in times of rising and falling asset prices beyond that warranted by fundamentals in the hope of achieving macroeconomic stability. On the other hand opponents ${ }^{2}$ of a proactive monetary policy argue that it is difficult for monetary authorities to identify when asset price misalignments occur, and if possible, whether monetary policy can in fact bring asset prices back in line with their fundamentals without creating a recession. Accordingly, monetary policy should follow a reactive approach where the authorities wait and see whether asset price reversals occur, and react in an ex post accommodative manner to the extent that these reversals affect output and inflation stability. In either case both approaches effectively assume that monetary policy can affect asset prices. Therefore from the perspective of monetary policy makers it is important to have reliable estimates of how asset prices react to monetary policy instruments for policy decisions to be effective.

Most studies that set out investigating the relationship between asset prices, mainly stock prices, and monetary policy have done so for developed economies, while only a few papers have attempted to empirically verify this relationship for emerging markets. This study investigates the relationship between monetary policy and stock prices in five emerging Middle Eastern economies; Kuwait, Oman, Saudi Arabia, Egypt and Jordan.

The number of studies examining monetary policy for these countries is very scarce. For the members of the Gulf Cooperation Council (GCC), Kuwait, Oman and Saudi Arabia, the emphasis of these studies is mainly on the traditional monetary transmission mechanisms such as the interest rate and bank lending channels. For instance Cevik and Teksoz (2012) find that these channels are relatively effective in influencing non-hydrocarbon output and consumer prices while the exchange rate channel does not appear to play an important role. Prasad and Espinoza (2012) examine the pass-through of policy rates to retail rates and find that it is on the low side. The main reason for the lack of motivation for such studies is that a peg to the US dollar provides a nominal anchor for monetary policy in these countries. Therefore given the openness of capital accounts it is reasonable to expect that their policy rates closely follow the US rates with limited scope for monetary independence. Bova and Senhadji (2009) have investigated the interest rate convergence between the GCC rates and the US and find that the covered interest rate parity ${ }^{3}$ holds, although with some

\footnotetext{
${ }^{1}$ See for example Cecchetti et al. (2000); Bordo and Jeanne (2002); Roubini (2006) among others.

${ }^{2}$ See for example Bernanke and Gertler $(1999,2001)$.

${ }^{3}$ Under the assumption of free capital flow and perfect substitutability between domestic and foreign assets, the covered interest rate parity states that the forward premium of a foreign currency should be equal to the interest rate differential between the two assets.
} 
difference across countries. However they also note that in the short run there is some degree of manoeuvring space where negative and positive interest rate spreads have been purposely maintained by central banks to reduce inflation, counter exchange rate speculation and stimulate economic activity and stock market performance, as was the case after the stock market crash in 2006. They also conclude that Kuwait, which allows for a relatively more flexible exchange rate, and Oman which imposes relatively stricter restrictions on capital movements, have followed the US monetary policy less closely than the rest of the GCC countries.

Poddar et al. (2006) consider the interest rate, bank lending, exchange rate and asset prices channels in Jordan. They use a structural vector autoregressive (SVAR) approach and identify the exogenous shocks using a standard recursive ordering where stock prices is ordered before the policy rate. They find that monetary policy is generally ineffective in affecting output, the exchange rate or asset prices. Like the GCC countries Jordan also pegs its currency to the US dollar, however Maziad (2009) finds that the Jordanian central bank maintains some autonomy over the short run to respond to developments in inflation and output.

The Egyptian financial sector is relatively more developed and inflation targeting is the main framework anchoring monetary policy. Al-Mashat and Billmeier (2008) also employ a structural vector autoregression model to examine the effectiveness of monetary policy. They find that the exchange rate channel plays a strong role in propagating monetary shocks to output and prices, while the bank lending and asset pricing channels are weak. Policy rates are also ordered last in their identification scheme, restricting stock prices to respond only with a lag to monetary shocks. Arbatli and Moriyama (2011) find similar results however they do not consider asset prices in their model.

The current paper attempts to fill the gap in the literature on monetary policy by being the first to consider the interaction between monetary policy and stock prices in Kuwait, Oman and Saudi Arabia using the structural vector autoregression approach. In addition, there exists a simultaneity problem when trying to empirically investigate the relation between stock prices and monetary policy. Given the forward looking nature of stock prices it does not seem reasonable to assume that stock prices will not respond immediately to a monetary policy shock, at the same time it is also not reasonable to assume that monetary policy only responds with a delay towards stock price shocks. Therefore using recursive short run restrictions to identify structural shocks in a VAR framework greatly undermines the empirical investigation. This paper follows Bjørnland and Leitemo (2009) in employing Blanchard and Quah (1989) long run restrictions to identify the structural shocks between stock prices and monetary policy. By assuming that money neutrality holds in the long run, the short run relationship governing stock prices and monetary policy is left unrestricted. Thus contrary to Poddar et al. (2006) and Al-Mashat and Billmeier (2008) it is assumed that monetary policy and stock prices can respond to each other's shocks in the short run, thus providing a more accurate empirical depiction of the relationship. Moreover many firms operating in the individual countries may be import or export oriented, thus the real exchange rate might play an important role in influencing these firms' profitability and consequently their stock prices. For this reason the SVAR model is extended to include the real exchange rate.

The next section discusses the relationship and simultaneity problem between monetary policy and stock prices and exchanges rates, and between stock prices and exchange rates in more detail. Section three presents the SVAR method and the different identification schemes it uses to solve the simultaneity problem. 
A selective literature review is given in section four showing mainly the identification schemes employed in the literature, while this paper's identification scheme is presented in section five. Section six discusses the data and model specification and the results are presented in section seven. Finally, the last section provides a brief discussion of the results and concludes.

\section{$2 \quad$ Monetary policy and asset prices}

\subsection{The effect of monetary policy on stock prices}

There is a general consensus among economists that monetary policy plays a significant role in stock price movements. ${ }^{4}$ Starting from the dividend discount model for stock valuation, monetary policy which affects market interest rates is predicted to affect stock prices through two main channels (Smirlock and Yawitz (1985)). First a contractionary monetary policy which may be conducted through increasing policy rates, will eventually lead to a rise in the market interest rates that are used by investors to discount expected future cash flows resulting in lower stock prices. The second channel is through its impact on expectations of future cash flows such as earnings of the firm. To the extent that a monetary policy contraction can influence real economic activity it will affect the future earning potential of firms. As explained by Bernanke and Gertler (1995) for instance, a rise in interest rates caused by a monetary tightening can reduce firm's net cash flows by the extent that it leads to a fall in aggregate demand and consumer spending and an increase in interest expenses paid. Additionally the market interest rate rise would lead to a deterioration of the firm's financial position, causing it to face a higher external finance premium. This forces it to cancel or postpone profitable investment opportunity and thus lowering its potential future earnings. On the other hand the tight monetary condition can curtail the supply of credit provided by commercial banks to firms.

Bernanke and Kuttner (2005) also empirically investigate through which channels monetary policy affects stock prices. In addition to those previously mentioned they find evidence supporting a third channel which operates through the risk premium on stocks. The looming expectations of a recession brought about by the tightening monetary conditions could lead investors to view stocks as more risky investments especially with the increased volatility during the downturn. To compensate for the increase in perceived riskiness investors will demand a higher return which can only be achieved through lower stock prices.

Finally monetary policy can affect stock prices through the traditional liquidity channel as in Hamburger and Kochin (1972) and Mishkin (1996). Monetary policy that curtails liquidity will in general force the public to liquidate assets to increase their money holdings. Among these assets are stocks which would eventually lead to a reduction in their prices.

\subsection{The response of monetary policy to stock prices}

The main focus of monetary policy is to respond to actual and forecasted inflation and the output gap in order to minimize economic fluctuations. However there are a number of reasons why monetary authorities may consider asset prices in general and stock prices in particular when setting monetary policy.

\footnotetext{
${ }^{4}$ Given the forward looking nature of financial markets participants, it is expected that it is the unanticipated monetary policy changes that can impact stock prices as anticipated or expected monetary policy would have already been incorporated in stock prices.
} 
Stock prices play an important role in the transmission of monetary policy. For instance Tobin (1969) defines $q$ as the ratio of a firm's market value to replacement cost of capital and asserts that a rise in $q$ makes new capital relatively cheaper for firms, thus increasing investment incentives. Additionally a rise in stock prices can affect aggregate demand by increasing household wealth which can increase consumption expenditure. Moreover a fall in stock prices will reduce the value of collaterals that can be posted by economic agents to borrow, affecting aggregate demand (Bernanke et al. (1996) and Bernanke and Gertler (1989)). Thus stock prices form important channels through which monetary policy affects its inflation and output target variables.

The information in stock prices may also be used by central bankers in formulating monetary policy. Stock prices are forward looking variables that reflect expected changes in fundamentals, thus policy makers may use them as leading indicator variables for their target variables. Furthermore Alchian and Klein (1973) argue that asset prices should be included in the measurement of inflation as they represent current prices of claims on current and future consumption. Vickers (2000) presents a separate line of argument for including asset prices within the measure of inflation to which monetary policy responds. He contends that including asset prices would reduce the bias of the delayed response of monetary authorities to inflationary pressures.

Finally there is an ongoing debate in the literature on monetary policy and between practitioners on whether asset prices should be among the monetary policy target variables. As pointed out previously asset prices such as stock prices can have a direct effect on output and inflation. In the absence of efficient capital markets asset prices can deviate and disconnect from fundamentals, and volatility within these markets become an independent source of economic instability which policy makers should respond to. Bordo and Jeanne (2002), Cecchetti et al. (2000) and Roubini (2006) argue that in order to avoid the financial instability that is brought about by asset prices boom bust cycles, monetary policy should intervene and primitively burst asset price bubbles to bring them in line with their underlying fundamentals.

\subsection{Monetary policy and the exchange rate}

Another asset class that plays an important role in the formulation of monetary policy is the exchange rate. Similarly as with the price of stocks the relationship with monetary policy is endogenous, especially for open economies. Monetary policy has a direct impact on exchanges rates where a contractionary policy that increases domestic interest rates makes domestic currency deposits more attractive than foreign currency deposits. This leads to an inflow of capital, and thus appreciating the domestic currency relative to the foreign currencies. Assuming rational expectations and nominal rigidities this will in turn impact, at least in the short run, the real exchange rate, real net exports and thereby real GDP (Taylor (1995)). However Stiglitz (1999) argues that this relationship might not hold during periods of financial crisis were interest rate hikes might increase the risk of bankruptcy leading to loss of confidence and capital outflows. Caporale et al. (2005) examine this issue during the Asian crisis and conclude that during the crisis interest rate increases contributed to the collapse of the domestic currencies. At the same time exchange rates are usually important determinants of monetary policy stance. In addition to its impact on aggregate demand, exchange rates can have a substantial impact on consumer prices especially in small open economies. A depreciation in the domestic currency makes imported goods and services more expensive and whether these imports are finished goods or used as inputs for production, the rise in their prices will pass through to the consumer price index. Concurrently demand for domestic goods will rise to substitute the more expensive imports adding to 
the pressure on the price index. Foreign demand on the domestic goods will also rise as they become cheaper relative to the foreign goods. Thus depending on the weight given to inflation in the monetary authorities' loss function, exchange rates will play a significant role in determining monetary policy especially in small open economies.

\subsection{Stock prices and the exchange rate}

The relationship between stock prices and exchange rates is not as straightforward as between these financial variables and monetary policy. There are two main models that attempt to determine exchange rate and stock price interactions, "flow oriented" models postulated by Dornbusch and Fischer (1980) and the "stock oriented" model of Branson et al. (1977).

Flow models emphasize the role of exchange rates in determining the international competitiveness of exporting firms. For instance an appreciation of the domestic currency would make exports more expensive and thus less competitive reducing foreign demand and firm's earnings, and consequently its value which will be reflected in a lower stock price. Adler and Dumas (1984) also note that even firms that only operate domestically can be affected by such an appreciation. The appreciation of the currency will make imports used as inputs for production cheaper and thus increase the profitability of these firms, increasing their stock price.

On the other hand stock models stress on the role stock markets play in determining capital flow movements. A rise in domestic stock prices can attract portfolio inflows increasing the demand on the domestic currency and causing it to appreciate. Note that causation here runs from the stock prices to the exchange rate, but this would require stock markets to be large and liquid enough to impact the exchange rate which is not the case for many emerging stock markets. However it is also important to note that exchange rate movements can induce changes in stock prices through portfolio flows. A currency depreciation, in economies that attempt to maintain a managed float exchange rate system but faces the risk of not being able to hold the exchange rate within the target bands due to low foreign reserves, can induce a panic and lead to considerable capital outflows from all asset categories. This will cause a fall in the prices of stocks in these economies.

\section{The simultaneity problem and the structural vector autoregres- sion approach}

The ongoing revolutions in the information technologies have dramatically lowered the costs of acquiring and processing information. They have also considerably increased the amount and accuracy of information and the speed of its dissemnation. This has led to a fast paced financial market with highly knowledgeable and sophisticated market participants. It is thus reasonable to assume that the response of market participants and policy makers to developments in financial markets is instantaneous. Therefore a major problem that faces studies investigating the interactions between monetary policy and stock prices is the endogeneity of the variables. That is, as stock prices may respond to monetary policy decisions, monetary policy

may simultaneously respond to stock price movements. This contemporaneous relationship between these two variables makes it impossible to identify the true structural parameters linking them together, without imposing further restrictions on the relationship. The difference between the empirical studies investigating 
this relationship has been mainly in the different methods employed to correctly identify the true structural parameters. In what follows is a brief description of the most popular approach to deal with this endogeneity problem which is the Structural Vector Autoregression approach.

Consider the following system of simultaneous equations which govern the dynamic relationship between $n$ macroeconomics variables ${ }^{5}$

$$
\begin{gathered}
\Gamma Y_{t}=B(L) Y_{t}+\varepsilon_{t} \\
\varepsilon_{t} \sim \operatorname{iid}\left(0, \Sigma_{\varepsilon}\right)
\end{gathered}
$$

where $Y_{t}$ is an $n \times 1$ vector of stationary macroeconomic variables, $\Gamma$ is an $n \times n$ matrix of coefficients governing the contemporaneous relationships between the variables. $B(L)$ is a matrix polynomial in the lag operator $L$ such that $B(L)=B_{1} L+B_{2} L^{2}+\cdots+B_{p} L^{p}$. Finally $\varepsilon_{t}$ is a $n \times 1$ vector of the unexpected structural shocks with a diagonal variance - covariance matrix $\Sigma_{\varepsilon}$.

Equation (1) must be transformed into its reduced form by pre-multiplying it with $\Gamma^{-1}$, assuming it exists, to give the reduced form VAR

$$
\begin{gathered}
Y_{t}=\Gamma^{-1} B(L) Y_{t}+\Gamma^{-1} \varepsilon_{t} \\
Y_{t}=A(L) Y_{t}+u_{t}
\end{gathered}
$$

where $A(L)=\Gamma^{-1} B(L), u_{t}=\Gamma^{-1} \varepsilon_{t}$, i.e. $\varepsilon_{t}=\Gamma u_{t}$. The reduced form errors $u_{t}$ are linear combinations of the structural errors $\varepsilon_{t}$ with variance - covariance given by $\Sigma_{u}=\Gamma^{-1} \Sigma_{\varepsilon} \Gamma^{-1^{T}}$.

Equation (3) can be estimated directly using OLS giving us $n^{2} p$ coefficients in $A(L)$, where $p$ is the number of lags included in the model, and $(n(n+1)) / 2$ variance parameters in $\Sigma_{u}$ which is symmetric. In order to retrieve the $n^{2}+n^{2} p+(n(n+1)) / 2$ structural parameters in $\Gamma, B(L)$ and $\Sigma_{\varepsilon}, n^{2}$ restrictions are required to correctly identify them.

One of the main identification approaches employed in the SVAR literature is to restrict the structural innovations to be uncorrelated, this requires the structural variance - covariance matrix to be diagonal. Bernanke (1986, p. 52) writes that he thinks of the structural innovations 'as primitive exogenous forces not directly observed by the econometrician which buffet the system and causes oscillations. Because these shocks are primitive, i.e., they do not have common causes, it is natural to treat them as approximately uncorrelated'. In essence, the SVAR method treats all variables as endogenous but decomposes them into their expected and unexpected parts, and by focusing on the unexpected structural shocks or surprises, the SVAR method is able to pin down the causality which runs from the shocked variable to the other variables in the model. In the monetary policy SVAR literature these structural shocks can be regarded as unexpected exogenous changes in monetary policy after controlling for monetary policy actions in response to nonmonetary developments in the

\footnotetext{
${ }^{5}$ The vector of constants is suppressed here without loss of generality.
} 
economy. Christiano et al. (1999) suggest changes in the monetary authorities' preferences as a source from which exogenous monetary policy shocks could come about. The orthogonality condition imposes $(n(n-1)) / 2$ restrictions, leaving $(n(n+1)) / 2$ remaining to achieve identification. Another standard restriction is in fact a normalization process where the diagonal elements of the contemporaneous coefficient matrix are set equal to unity. Equivalently the normalization can be applied to the diagonal elements of the structural variance - covariance matrix leaving the diagonal elements in the contemporaneous coefficient matrix unrestricted. This second normalization is convenient as it sets the variance of the structural shocks equal to unity making a standard deviation shock correspond to a unit shock in the structural innovations. This normalization imposes another $n$ restrictions leaving only $(n(n-1)) / 2$ remaining for identification.

In most SVAR studies the remaining restrictions are a recursive casual ordering ${ }^{6}$ of $\Gamma$ such that it becomes lower triangular. This means that the lower ordered variables are not allowed to affect the proceeding variables contemporaneously. This is one way to solve the simultaneity problem however it should be justified on economic grounds.

The reduced form VAR in equation (3) can be transformed into a moving average representation, under the assumption of stability, by rearranging it to obtain

$$
\begin{gathered}
Y_{t}=(I-A(L))^{-1} u_{t} \\
Y_{t}=C(L) u_{t}
\end{gathered}
$$

where $C(L)=(I-A(L))^{-1}$. Thus each variable is expressed as a function of current and past reduced form innovations. Furthermore the structural moving average representation can be obtained by replacing $u_{t}$ by $\Gamma^{-1} \varepsilon_{t}$ such that

$$
Y_{t}=C(L) \Gamma^{-1} \varepsilon_{t}=\Theta(L) \varepsilon_{t}
$$

where $\Theta(L)=C(L) \Gamma^{-1}=\Gamma^{-1}+C_{1} \Gamma^{-1} L+\cdots$, so that the variables are now expressed as functions of current and past structural innovations. This representation is particularly useful as it provides us with a tool of analysis which enables us to see how an unexpected shock impacts the variables at different time periods into the future, the impulse response functions. Note that restrictions can also be imposed on $\Gamma^{-1}$ instead of $\Gamma$, for example, a recursive causal ordering of $\Gamma^{-1}$ implies that structural shocks of lowered ordered variables are not allowed to contemporaneously affect the preceeding variables.

Given this moving average representation of the SVAR a new set of restrictions can be applied to govern the long run relationships between the variables. Specifically, if some of the variables are integrated of order one but not cointegrated, i.e. no long run relationship exists, then a shock to one of the variables should have no long run impact on the level of the non-cointegrated $I(1)$ variable. Therefore if variables in $Y_{t}$ are specified in first differences then the impact of the structural shock $\varepsilon_{j}$ on $\Delta y_{i}$ after $h$ periods is given by $\theta_{i j, h}$, whereas

\footnotetext{
${ }^{6} \mathrm{~A}$ recursive VAR amounts to estimating the reduced form and then computing the Cholesky factorization of the reduced form VAR variance - covariance matrix. This is why this identification scheme is also called Cholesky decomposition.
} 
the long run impact on the level of $y_{i t}$ is given by the cumulative sum of lagged coefficients $\Sigma_{h}^{\infty} \theta_{i j, h}=\theta_{i j}(1)$. Writing the long-run expression of $C(L) \Gamma^{-1}=\Theta(L)$ as

$$
C(1) \Gamma^{-1}=\Theta(1)
$$

it can be seen that imposing long-run restrictions by setting the necessary elements of $\Theta(1)$ to zero can help pin down the elements in $\Gamma^{-1}$ since $C(1)$ is observable by the inversion of $A(1)$ which is directly estimated from the reduced form equation (3). Applying such long run restrictions enables us to free some of the restrictions applied to the contemporaneous coefficients. These long run restrictions were first proposed by Blanchard and Quah (1989).

Faust and Leeper (1997) criticize the sole use of long run infinite horizon identifying restrictions in finite samples showing that these types of restrictions may not elicit unique short run dynamics. They recommend imposing additional short run restrictions or restating the long run restrictions such that it binds at finite horizons. Moreover they argue that in low dimension models, such as the one used by Blanchard and Quah (1989) which only includes output and unemployment, different structural shocks maybe confounded.

Other identification restrictions that have been employed within the SVAR context has been identification through heteroskedasticity, first proposed by Rigobon (2003) and Rigobon and Sack (2003). In this approach the heteroskedasticity present in the data is used to identify different regimes for the variance - covariance matrix of the reduced form innovations. The additional regimes provide new restrictions which may be used to identify the structural parameters. Another identification approach is the use of sign restriction on the impulse response functions as proposed by Canova and Nicolo (2002) and Uhlig (2005). These sign restrictions are based on priori consensual considerations, such as a contractionary monetary policy shock is not expected to increase real GDP. A problem with relying purely on sign restrictions is that identification will not be unique. Fry and Pagan (2011) show that due to the weakness of information contained in sign restriction, there will be many impulse responses that can satisfy each sign restriction. Furthermore, Paustian (2007) and Canova and Paustian (2011) show that sign restrictions can only uniquely identify the unconstrained impulse responses when the imposed restrictions are numerous, otherwise, the identified shocks will be composed of a hybrid of shocks without clear economic interpretation.

\section{Identification}

The SVAR model in this investigation includes five variables, output, a price index, real exchange rate, real stock prices and a monetary policy instrument variable. This means twenty five restrictions are required to fully indentify the structural parameters governing the relationships between these variables.

The standard restrictions that the structural variance - covariance matrix $\Sigma_{\varepsilon}$ is diagonal and normalized so that the diagonal elements are unity is applied. This means we can interpret the structural shocks as exogenous, i.e. deviations from the monetary policy rule, and pins down the causality to run from the shocked variable to the other variables included in the model. This leaves ten restrictions remaining to achieve identification. Eight restrictions are applied on the contemporaneous structural coefficients. Following standard monetary policy SVAR literature it is assumed that the macroeconomic variables, output and inflation, respond only with a lag to the financial and monetary variables' exogenous shocks, while they in 
turn respond immediately to the macroeconomic variables' exogenous shocks. ${ }^{7}$ With regards to the financial variables and monetary instrument, the real stock price and real exchange rate are left to react simultaneously to the monetary policy shocks, while real exchange rates are restricted to react to real stock price shocks only with a lag. Given the order of the variables in the model as mentioned previously, the short run restrictions imposed imply the following relationship between the structural shocks and the endogenous variables.

$$
\begin{aligned}
& Y_{t} \Gamma^{-1} \quad \varepsilon_{t} \\
& {\left[\begin{array}{c}
\text { output } \\
\text { priceindex } \\
\text { exchangerate } \\
\text { stock price } \\
\text { policy rate }
\end{array}\right]=C(L)\left[\begin{array}{ccccc}
\gamma_{11} & 0 & 0 & 0 & 0 \\
\gamma_{21} & \gamma_{22} & 0 & 0 & 0 \\
\gamma_{31} & \gamma_{32} & \gamma_{33} & 0 & \gamma_{35} \\
\gamma_{41} & \gamma_{42} & \gamma_{43} & \gamma_{44} & \gamma_{45} \\
\gamma_{51} & \gamma_{52} & \gamma_{53} & \gamma_{54} & \gamma_{55}
\end{array}\right] \quad\left[\begin{array}{c}
\varepsilon_{\text {output }} \\
\varepsilon_{\text {price index }} \\
\varepsilon_{\text {exchange rate }} \\
\varepsilon_{\text {stock price }} \\
\varepsilon_{\text {policy rate }}
\end{array}\right]}
\end{aligned}
$$

The final two restrictions are based on the concept of money neutrality, where it is not expected that nominal variables could have an effect on real economic variables in the long run. We follow Bjørnland (2009) and Bjørnland and Leitemo (2009) in restricting monetary policy shocks to have no long run impact on the real exchange rate or stock prices in the long run. In their study on the US market Bjørnland and Leitemo (2009) find, similar to other studies (Patelis (1997), Thorbecke (1997) and Neri (2004)) which only rely on contemporaneous restrictions to achieve identification, that monetary policy does lead to a fall in stock prices, however the magnitude of the impact is significantly larger. They argue that the reason behind the difference in magnitude is that restricting the contemporaneous relationships between monetary policy and stock prices can rule out potentially important channels of interaction which if empirically relevant would bias the results. These restrictions are imposed by setting $\theta_{35}(1)=\theta_{45}(1)=0$ so that the full matrix for the expression $C(1) \Gamma^{-1}=\Theta(1)$ is written as

$$
\left[\begin{array}{lllll}
C_{11}(1) & C_{12}(1) & C_{13}(1) & C_{14}(1) & C_{15}(1) \\
C_{21}(1) & C_{22}(1) & C_{23}(1) & C_{24}(1) & C_{25}(1) \\
C_{31}(1) & C_{32}(1) & C_{33}(1) & C_{34}(1) & C_{35}(1) \\
C_{41}(1) & C_{42}(1) & C_{43}(1) & C_{44}(1) & C_{45}(1) \\
C_{51}(1) & C_{52}(1) & C_{53}(1) & C_{54}(1) & C_{55}(1)
\end{array}\right] \Gamma^{-1}=\left[\begin{array}{cccccc}
\theta_{11}(1) & \theta_{12}(1) & \theta_{13}(1) & \theta_{14}(1) & \theta_{15}(1) \\
\theta_{21}(1) & \theta_{22}(1) & \theta_{23}(1) & \theta_{24}(1) & \theta_{25}(1) \\
\theta_{31}(1) & \theta_{32}(1) & \theta_{33}(1) & \theta_{34}(1) & 0 \\
\theta_{41}(1) & \theta_{42}(1) & \theta_{43}(1) & \theta_{44}(1) & 0 \\
\theta_{51}(1) & \theta_{52}(1) & \theta_{53}(1) & \theta_{54}(1) & \theta_{55}(1)
\end{array}\right]
$$

where

$$
\begin{aligned}
& C_{31}(1) \gamma_{15}+C_{32}(1) \gamma_{25}+C_{33}(1) \gamma_{35}+C_{34}(1) \gamma_{45}+C_{35}(1) \gamma_{55}=0 \\
& \text { and } \\
& C_{41}(1) \gamma_{15}+C_{42}(1) \gamma_{25}+C_{43}(1) \gamma_{35}+C_{44}(1) \gamma_{45}+C_{45}(1) \gamma_{55}=0 .^{8}
\end{aligned}
$$

\footnotetext{
${ }^{7}$ Output has been placed before inflation such that an output shock can impact prices immediately but responds to it with a delay. This follows standard SVAR literature such as Bagliano and Favero (1998).

${ }^{8}$ Estima's RATS sowftware has been used in order to implment the above restictions and the code is avialable upon request from the authors.
} 


\section{Data and model specification}

As asset prices in general and stock prices in particular respond quickly to incorporate any new information that arises in the markets it seems appropriate to use the monthly frequency to investigate how stock prices respond to monetary policy innovations. Therefore the sample of countries and period chosen to carry out this study is constrained by the availability of monthly observations for the different variables required. The sample covers the period from November 2003 to December 2012 for all countries Kuwait, Oman, Saudi Arabia, Egypt and Jordan. The industrial production index is used as a measure of real output for Egypt and Jordan, while the crude oil production index is used for Saudi Arabia, Kuwait and Oman. ${ }^{9}$ The rest of the variables are the Consumer Price Index, the Dollar Real Exchange Rate and Real Stock Prices deflated by the corresponding CPI.

The policy rates used to measure the monetary stance are the central's bank discount rate for Egypt and Jordan and the overnight interbank rate for Oman. For Saudi Arabia and Kuwait we follow Cevik and Teksoz (2012) in using the three month interbank rate because it is the only rate available for the full sample period.

Given the importance of the exchange rates in these countries and the role it plays in monetary policy objectives to achieve price stability, the US Federal Funds Rate is included in the model to appropriately measure the monetary shock. In addition the price of crude oil is included as another exogenous variable.

All data has been obtained from Reuters' Datastream and the International Financial Statistics of the IMF databases. All variables with the exception of the policy rates are expressed in natural logarithms. Bjørnland and Leitemo (2009) note that it is important that the variables in the VAR are stationary; otherwise the moving average representation may be non-convergent. Augmented Dickey-Fuller (Dickey and Fuller (1979)) and Phillips and Perron (1988) unit root test are performed on all variables. Generally the results show that all variables are integrated of order one in levels and thus all variables are entered in the VAR in first differences.

Since long run restrictions are imposed in this study it is important that no cointegration relationships exists between the variables in levels on which the restrictions applies, that is the policy rates, the real exchange rate and the real stock price. Thus Johansen cointegration Johansen $(1991,1995)$ test has been performed on all variables for all countries in order to establish if any long run relationships exist. We find no evidence of any cointegration relationships. Finally the lag length is chosen so that the residuals of the models are whitened. Four lags have been chosen for all countries and no evidence of serial autocorrelation or heteroskedasticity is found in the residuals using the LM autocorrelation and White heteroskedasticity tests.

\footnotetext{
${ }^{9}$ The crude oil production index is used given the unavailability of an industrial production index or GDP measure at a monthly frequency. Given that oil production is considered the main component of industrial production in Saudi Arabia, Kuwait and Oman (Kim and Hammoudeh (2013)) the oil production index is expected to act as a good proxy for economic activity in these countries.
} 


\section{Results of impulse response analysis}

\subsection{Recursive ordering (Cholesky decomposition)}

For the sake of comparison the impulse response functions from the Cholesky decomposition are presented first, where the interest rate is ordered before stock prices. The first column in figure (1) gives the response of real stock prices to a monetary policy shock which is normalized so that it leads to an increase in the interest rate by one percentage point. The solid lines represent the accumulated impulse responses while the dashed lines represent the probability bands at the 0.16 and 0.84 fractiles which correspond to one standard deviation. The reactions of the stock prices are generally in the right direction with considerable variation in the dynamics and magnitudes. For Kuwait the impact of the monetary tightening takes effect two periods after the initial shock and is positive, but it turns negative during the fifth period indicating a fall in prices by $2.5 \%$ before settling at a rise of nearly $1 \%$ above its previous level. The response of Oman's stock price on the other hand is more in line with theory, where the stock prices fall by around $6 \%$ during the second period before returning very close to their previous levels. The impulse response of the Saudi stock prices is the reverse pattern of that of Kuwait, where the initial impact is negative at around $2 \%$ during the second period, turning positive during the third period at $2 \%$ before settling down at a permanent $6 \%$ fall in stock prices. The real stock prices in the Egyptian market are greatest in terms of magnitude. The initial one percent rise in the interest rate leads to a $10 \%$ fall in stock prices by the second period and then eventually rises to turn positive by the eighth period, the price remains higher by $10 \%$. Similarly the Jordanian stock price falls during the first four periods, although by nearly half the magnitude, it turns positive thereafter and continues to increase. The effects of the contractionary monetary policy shock seems implausible in most these cases since it seems to have a permanent impact on the real stock price, especially for Kuwait, Egypt and Jordan where the impact is positive. However with the exception of Oman and Egypt none of these responses are statistically significant. Even for Oman and Egypt the significance although negative remains so for only the second time period. These results are the main motivation for using the assumption of money neutrality to restrict the long run impact of a monetary policy shock on real stock prices and exchange rates.

The second Column of figure (1) reports the response of real stock prices to a real exchange rate shock that leads to a one percentage point increase in the real exchange which corresponds to a depreciation. There are differences in the direction, magnitudes, dynamics and statistical significance of the responses; however the results are very similar to the response obtained using the long run money neutrality restrictions and thus the discussion of these results are deferred to the next section.

Before moving on to the money neutrality identification scheme it is worthwhile to look at the response of the rest of the variables to the monetary policy shock. Figure (3) in the appendix shows the accumulated responses of output, inflation and the real exchange rate to the monetary policy shock. The thing to note is the response of the real exchange rate to the monetary contraction. In all cases the increase in the interest rates leads to a persistent depreciation which is opposite to what is predicted by economic theory. This might be a sign of the unreliability of the results obtained from restricting the short run interactions between the financial variables of the model, especially that restricting monetary policy not to have an immediate impact

on the exchange rate. This also adds to the motivation behind using monetary neutrality to substitute some of the implausible short run restrictions with more plausible long run restrictions. 


\subsection{Identification under long run money neutrality}

The first column of figure (2) presents the accumulated impulse response functions of the real stock price to a monetary policy shock. Again shocks are normalized so that they correspond to a one percentage increase to the related variable and the dashed lines represent the probability bands at the 0.16 and 0.84 fractiles which correspond to one standard deviation.

An important difference from the previous impulse responses using Choelsky ordering is that stock prices respond to monetary policy on impact but not always in the warranted direction, however the cumulative impact turns negative by the second period for all countires expect for Saudi Arabia which only turns negative in the seventh period. For Kuwait and Egypt the magnitudes of the shocks are nearly the same as in the Cholesky ordering while it is significantly less for Oman and Saudi Arabia and greater for Jordan. The monetary policy shocks are only temporarily statistically significant for Kuwait and Egypt, where for Kuwait the stock prices fall by around 3\% after 6 months and for Egypt stock prices fall by around 11\% after three months before gradually returning to their previous level as the long run restriction bites.

Figure (4) in the appendix shows the impact of the monetary policy shock on output, inflation and the real exchange rate. The results seem more plausible than before. The monetary policy shock now leads to an appreciation of the real exchange rate on impact for all five countries. This is in line the famous Dornbusch (1976) hypothesis; however the appreciation is only significant in the case of Egypt where the real exchange rate falls by around $3 \%$ before returning to its previous level. Moreover the increase in the interest rates caused by the monetary policy shock brings down output in Kuwait, Oman, Saudi Arabia and Jordan, however the effect is only significant for Kuwait. In the case of Egypt output rises in response to the shock which could be caused by the appreciation of the exchange rate which makes imported goods used for production cheaper, however the rise in output is not statistically significant. The results in general are consistent with an increase in the dividend discount rate associated with the rise in interest rates and with the exception of Egypt it is also consistent with a downward revaluation in expected dividends due to the fall in output. Moreover with the exception of Kuwait the monetary policy shock also manages to reduce inflation for all countries but this is only significant in the case of Egypt where inflation falls by $2.5 \%$. In Kuwait and Saudi Arabia the price puzzle ${ }^{10}$ seems to be in operation, however it is much more severe for Kuwait.

The impact of the real exchange rate shock on stock prices is nearly the same as before and is highly persistent. Stock prices in Kuwait rise by about $4 \%$ in response to a $1 \%$ depreciation of the real exchange rate. This rise cannot be explained on the basis of increasing exports of domestic firms, as the great majority of firms listed on the Kuwaiti stock market operate domestically. Therefore a more viable explanation is given that Kuwait operates a managed float exchange rate regime, the temporary depreciation in the exchange rate can attract portfolio inflows which are partially invested in stocks, causing their prices to rise. In the case of Oman, Saudi Arabia and Egypt the depreciation causes a fall in stock prices by around $2.25 \%, 14 \%$ and $3.5 \%$ respectively. This could be due the high import component of goods used in production for domestic firms operating in these countries which leads to rising costs and lower profitability. Moreover, given the

\footnotetext{
${ }^{10}$ Christiano et al. (1999) argue that this can occur because the econometrician is not including, in the VAR, the same inflation indicator as the monetary authority. Therefore if the monetary policy tightens policy rates according to this missing indicator and inflation is only affected with a lag, then the contractionary monetary policy will be correlated with higher future inflation.
} 
relative instability of the exchange rate in Egypt, another reason for the fall of stock prices could be portfolio outflows that have been triggered by the initial depreciation which might be expected to bring about further depreciations. For Jordan the depreciation leads to an increase by around $3.5 \%$ in stock prices. According to the World Bank statistics exports constitute more than 50\% of the Jordanian GDP and thus a deprecation which makes the Jordanian goods cheaper will lead to increased foreign demand and thus increases the profitability of domestic firms. The response of the stock prices to a real exchange rate shock is however only statistically significant for Kuwait and Egypt. Responses of output, inflation and the interest rate to the real exchange rate shock are presented in figure (5) in the appendix. 
Figure 1: Impulse responses of stock prices using recursive ordering

Response of Stock Price to Monetary Policy Response of Stock Price to Exchange Rate

Kuwait
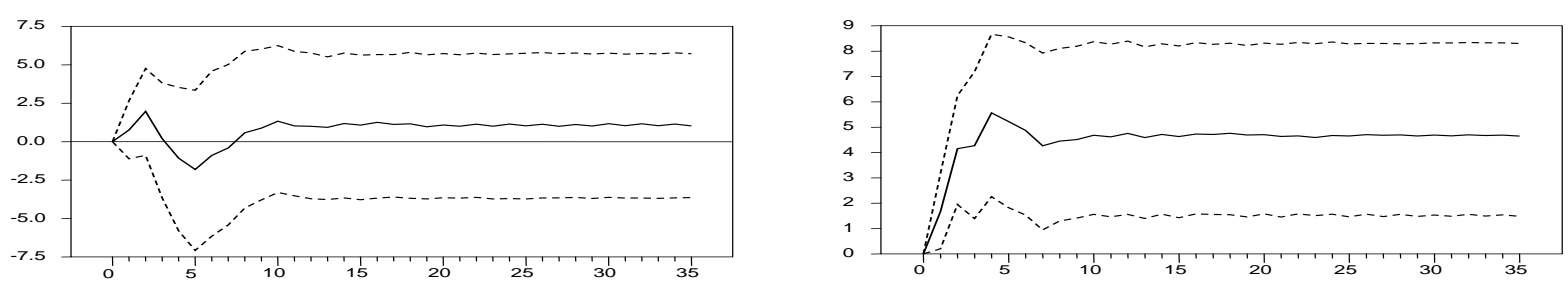

Oman
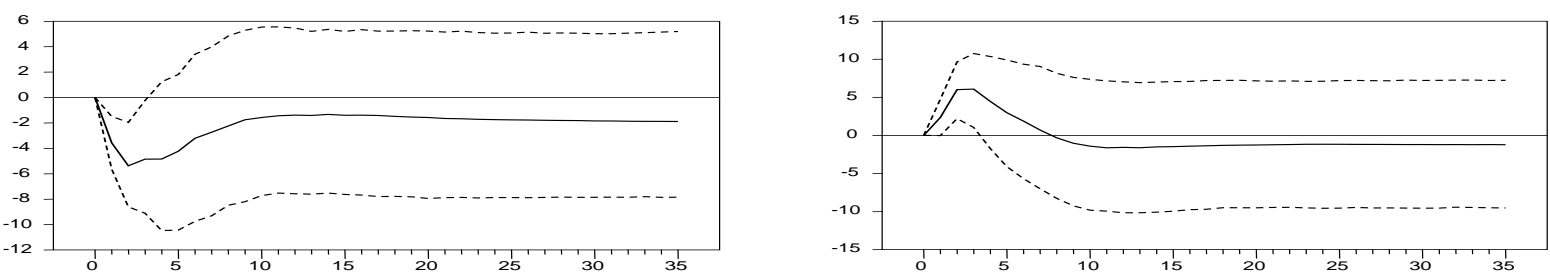

Saudi Arabia
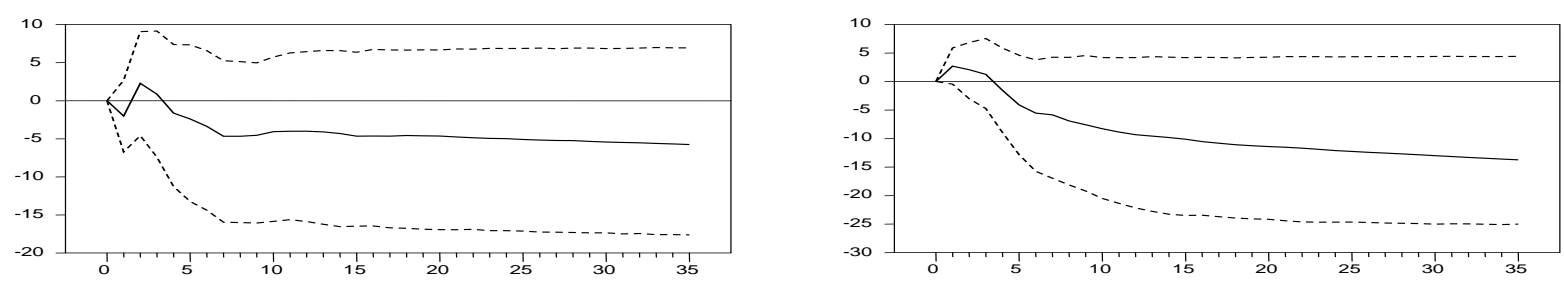

Egypt
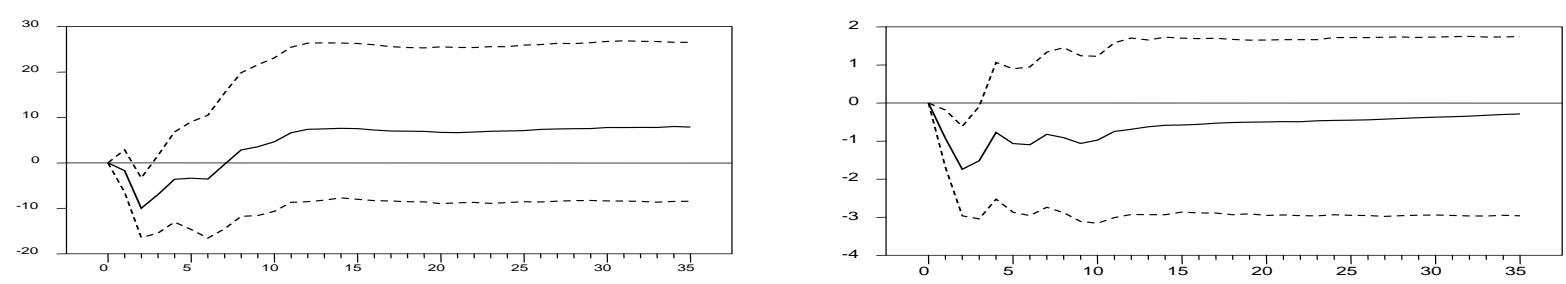

Jordan
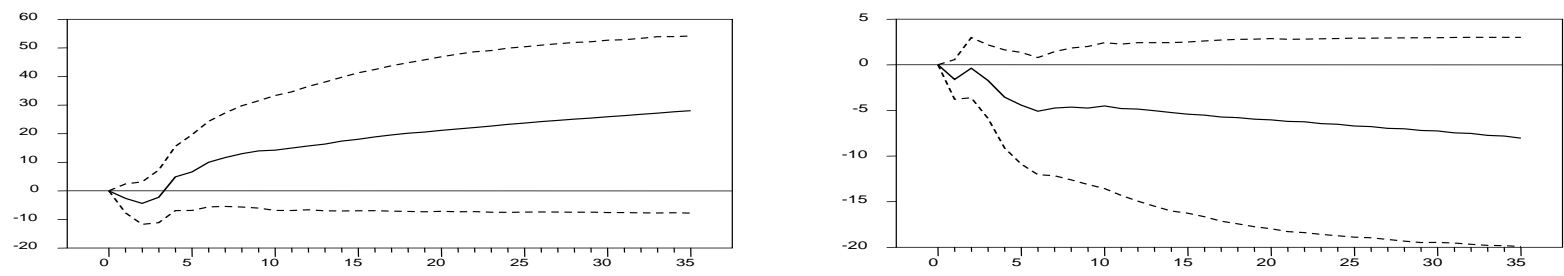

The probability bands are obtained using the method of Monte Carlo integration as in Doan (2010) with 2000 draws. 
Figure 2: Impulse responses of stock prices using long run and short run restrictions.

Kuwait
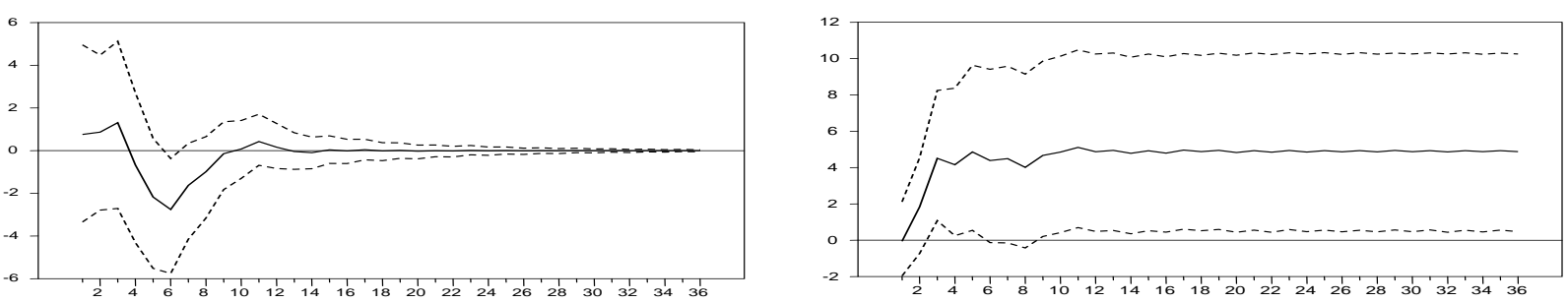

Oman
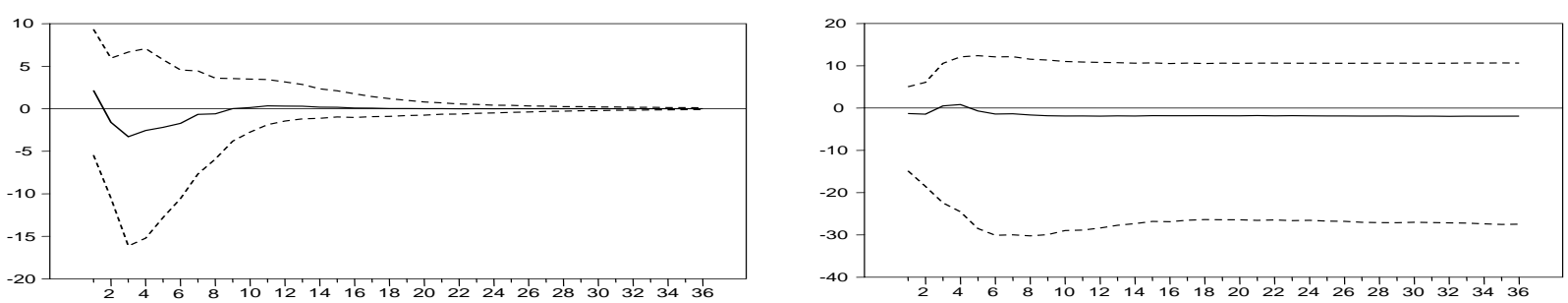

Saudi Arabia
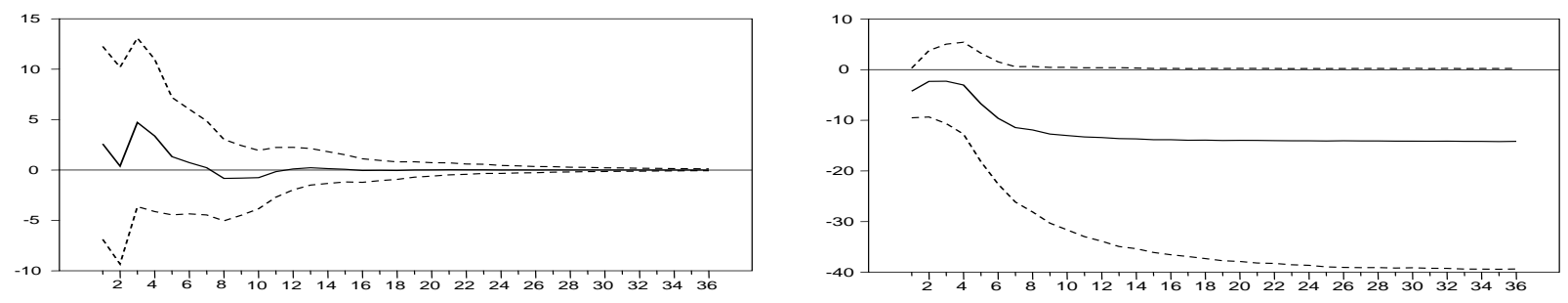

Egypt
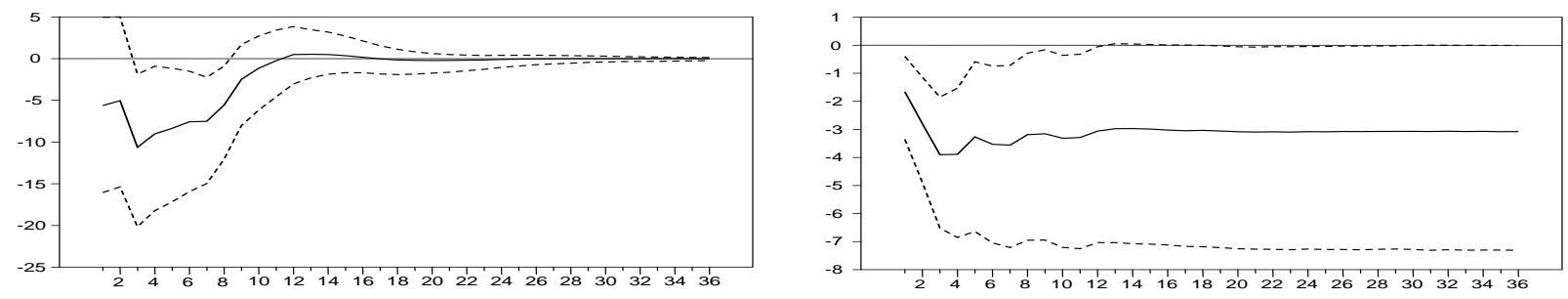

Jordan
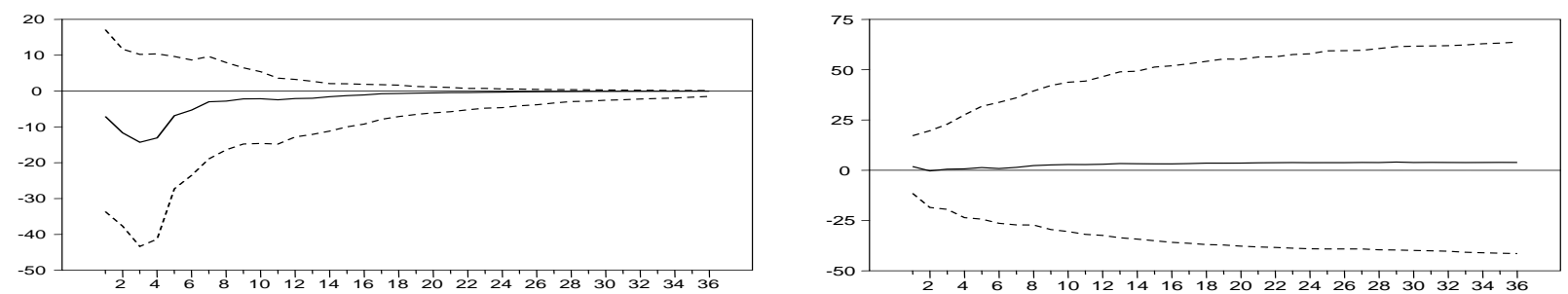

The probability bands are obtained using the method of Monte Carlo integration as in Doan (2010) with 10000 draws. 
Finally figure (6) in the appendix presents the response of the interest rate, real exchange rate, output and inflation to a one percent rise in stock prices. An important thing to note is that, although small in magnitude, there is a delayed appreciation of the real exchange rate. A potential explanation could be that the rise in stock prices attracts portfolio inflows which lead to the appreciation of the currency. The result is consistent for all countries however it is only statistically significant for Kuwait where the $1 \%$ rise in stock prices causes an appreciation of about $0.08 \%$. At the same time a stock price shock leads to a rise in output and inflation, expect for Egypt where only output rises. As Bjørnland and Leitemo (2009) point out this is consistent with a rise in consumption through a wealth effect and investment through the Tobin $q$ effect and thus leads to an increase in aggregate demand and, given the presence of nominal rigidities, inflation. The response of the interest rate is very small in magnitude and statistically insignificant in every case which may lead to the conclusion that stock prices are not among the monetary authorities' target variables for these countries.

\section{Conclusion}

This paper investigated the interactions between monetary policy, real stock prices and the real exchange rate in the light of the simultaneity problem between the financial variables. Five countries are examined; Kuwait, Oman, Saudi Arabia, Egypt and Jordan. For the three GCC countries; Kuwait, Oman and Saudi Arabia, this is the first paper to the best of our knowledge that has addressed this topic. For Egypt and Jordan studies are very scarce and do not apply convincing restrictions to solve the simultaneity problem and therefore the results obtained are questionable.

In this paper the results from a standard recursive ordering are presented first. In this ordering monetary policy is restricted not to impact output, inflation or the real exchange rate contemporaneously, while stock prices are restricted not to impact any of the variables contemporaneously. The results obtained are generally implausible as it shows a positive and persistent, although statistically insignificant, effect of monetary tightening on stock prices in three of the five countries. The impulse response functions obtained also show that the monetary policy shock is not well identified, as it leads in all cases to a depreciation of the real exchange rate. These results support the notion that applying contemporaneous restrictions on the financial variables might not be reasonable, given the fast paced nature of today's financial markets. Therefore, this paper investigates the relationship between these financial variables using the assumption of money neutrality to impose long run restrictions between the financial variables such that the contemporaneous relationships are left unrestricted. However it is still assumed that stock prices cannot impact the real exchange rate during the first period.

The results from the long run identification scheme seem more plausible as discussed earlier. The main results to note from this empirical investigation is that a monetary tightening leads to a fall in stock prices in all countries although with different dynamics and magnitudes. However the fall in stock prices are only statistically significant for Kuwait and Egypt. The difference between these two countries and the rest is that, as discussed earlier, they manage a relatively more independent monetary policy which allows for a more flexible exchange rate. Additionally it is also for both these countries that the real exchange rate can significantly affect stock prices, although the direction of the impact depends on the type of firms (export or import oriented) listed in the stock markets and the stability of the exchange rate regime. Thus the results 
support the possibility that monetary policy can have an effective role in the stock markets of these countries if it moves away from the exchange rate anchor and towards an inflation targeting framework.

Moreover, in examining the impact of stock price shocks on the real exchange rate, a consistent result is that an increase in the stock prices leads to an appreciation of the real exchange rate; however this was only significant for Kuwait and Oman. This can be a sign of the ability of stock markets in this region to attract portfolio inflows. Additionally regarding the impact of the stock price shock on output and inflation, in almost all cases an increase in stock prices leads to an increase in output and inflation. This refers to the possibility that stock markets can have a considerable role in affecting aggregate demand through the asset price channel of the monetary transmission mechanism. However this is only statistically significant for Saudi Arabia which has the largest stock market in the Middle East region in terms of market capitalization. Therefore as these stock markets develop and grow in size they may be able to play a considerable role in transmitting monetary policy shocks to the rest of the economy. 


\section{References}

Adler, M. and Dumas, B. (1984). Exposure to currency risk: Definition and measurement, Financial Management 13(2): pp. 41-50.

Al-Mashat, R. and Billmeier, A. (2008). The monetary transmission mechanism in egypt, Review of Middle East Economics and Finance 4(3): 32-82.

Alchian, A. A. and Klein, B. (1973). On a correct measure of inflation, Journal of Money, Credit and Banking 5(1): 173-91.

Arbatli, E. C. and Moriyama, K. (2011). Estimating a small open-economy model for egypt: Spillovers, inflation dynamics, and implications for monetary policy, IMF Working Papers 11/108, International Monetary Fund.

Bagliano, F. C. and Favero, C. A. (1998). Measuring monetary policy with var models: An evaluation, European Economic Review 42(6): 1069-1112.

Bernanke, B. and Gertler, M. (1989). Agency costs, net worth, and business fluctuations, American Economic Review 79(1): 14-31.

Bernanke, B. and Gertler, M. (1999). Monetary policy and asset price volatility, Economic Review (Q IV): $17-51$.

Bernanke, B., Gertler, M. and Gilchrist, S. (1996). The financial accelerator and the flight to quality, The Review of Economics and Statistics 78(1): 1-15.

Bernanke, B. S. (1986). Alternative explanations of the money-income correlation, Carnegie-Rochester Conference Series on Public Policy 25(1): 49-99.

Bernanke, B. S. and Gertler, M. (1995). Inside the black box: The credit channel of monetary policy transmission, Journal of Economic Perspectives 9(4): 27-48.

Bernanke, B. S. and Gertler, M. (2001). Should central banks respond to movements in asset prices?, American Economic Review 91(2): 253-257.

Bernanke, B. S. and Kuttner, K. N. (2005). What explains the stock market's reaction to federal reserve policy?, Journal of Finance 60(3): 1221-1257.

Bjørnland, H. C. (2009). Monetary policy and exchange rate overshooting: Dornbusch was right after all, Journal of International Economics 79(1): 64-77.

Bjørnland, H. C. and Leitemo, K. (2009). Identifying the interdependence between us monetary policy and the stock market, Journal of Monetary Economics 56(2): 275-282.

Blanchard, O. J. and Quah, D. (1989). The dynamic effects of aggregate demand and supply disturbances, American Economic Review 79(4): 655-73.

Bordo, M. D. and Jeanne, O. (2002). Monetary policy and asset prices: Does 'benign neglect' make sense?, International Finance 5(2): 139-64.

Bova, E. and Senhadji, A. (2009). Interest rate spread in the gcc: the role of monetary policy intervention. 
Branson, W. H., Halttunen, H. and Masson, P. (1977). Exchange rates in the short run: The dollardentschemark rate, European Economic Review 10(3): 303-324.

Canova, F. and Nicolo, G. D. (2002). Monetary disturbances matter for business fluctuations in the g-7, Journal of Monetary Economics 49(6): 1131-1159.

Canova, F. and Paustian, M. (2011). Business cycle measurement with some theory, Journal of Monetary Economics 58(4): $345-361$.

Caporale, G. M., Cipollini, A. and Demetriades, P. O. (2005). Monetary policy and the exchange rate during the asian crisis: identification through heteroscedasticity, Journal of International Money and Finance 24(1): $39-53$.

Cecchetti, S., Genberg, H., Lipsky, J. and Wadhwani, S. B. (2000). Asset Prices and Central Bank Policy. Geneva Reports on the World Economy 2, London, Centre for Economic Policy Research.

Cevik, S. and Teksoz, K. (2012). Lost in transmission? the effectiveness of monetary policy transmission channels in the gcc countries, IMF Working Papers 12/191, International Monetary Fund.

Christiano, L. J., Eichenbaum, M. and Evans, C. L. (1999). Chapter 2 monetary policy shocks: What have we learned and to what end?, Vol. 1, Part A of Handbook of Macroeconomics, Elsevier, pp. 65 - 148.

Dickey, D. A. and Fuller, W. A. (1979). Distribution of the estimators for autoregressive time series with a unit root, Journal of the American Statistical Association 74(366): pp. 427-431.

Doan, T. (2010). RATS Handbook for vector autoregressions, Estima, Evanstone.

Dornbusch, R. (1976). Expectations and exchange rate dynamics, Journal of Political Economy 84(6): 116176 .

Dornbusch, R. and Fischer, S. (1980). Exchange rates and the current account, American Economic Review 70(5): 960-71.

Faust, J. and Leeper, E. M. (1997). When do long-run identifying restrictions give reliable results?, Journal of Business 8 Economic Statistics 15(3): 345-53.

Fry, R. and Pagan, A. (2011). Sign restrictions in structural vector autoregressions: A critical review, Journal of Economic Literature 49(4): 938-60.

Hamburger, M. J. and Kochin, L. A. (1972). Money and stock prices: The channels of influence, Journal of Finance 27(2): 231-49.

Johansen, S. (1991). Estimation and hypothesis testing of cointegration vectors in gaussian vector autoregressive models, Econometrica 59(6): 1551-80.

Johansen, S. (1995). Likelihood-Based Inference in Cointegrated Vector Autoregressive Models, number 9780198774501 in OUP Catalogue, Oxford University Press.

Kim, W. J. and Hammoudeh, S. (2013). Impacts of global and domestic shocks on inflation and economic growth for actual and potential gcc member countries, International Review of Economics 83 Finance 27(C): 298-317. 
Maziad, S. (2009). Monetary policy and the central bank in jordan, IMF Working Papers 09/191, International Monetary Fund.

Mishkin, F. S. (1996). The channels of monetary transmission: Lessons for monetary policy, NBER Working Papers 5464, National Bureau of Economic Research, Inc.

Neri, S. (2004). Monetary policy and stock prices: theory and evidence, Temi di discussione (Economic working papers) 513, Bank of Italy, Economic Research and International Relations Area.

Patelis, A. D. (1997). Stock return predictability and the role of monetary policy, Journal of Finance 52(5): 1951-72.

Paustian, M. (2007). Assessing sign restrictions, The B.E. Journal of Macroeconomics 7(1): 1-33.

Phillips, P. C. B. and Perron, P. (1988). Testing for a unit root in time series regression, Biometrika 75(2): 335-346.

Poddar, T., Khachatryan, H. and Sab, R. (2006). The monetary transmission mechanism in jordan, IMF Working Papers 06/48, International Monetary Fund.

Prasad, A. and Espinoza, R. A. (2012). Monetary policy transmission in the gcc countries, IMF Working Papers 12/132, International Monetary Fund.

Rigobon, R. (2003). On the measurement of the international propagation of shocks: is the transmission stable?, Journal of International Economics 61(2): 261-283.

Rigobon, R. and Sack, B. (2003). Measuring the reaction of monetary policy to the stock market, The Quarterly Journal of Economics 118(2): pp. 639-669.

Roubini, N. (2006). Why central banks should burst bubbles, International Finance 9(1): 87-107.

Smirlock, M. J. and Yawitz, J. B. (1985). Asset returns, discount rate changes, and market efficiency, Journal of Finance 40(4): 1141-58.

Stiglitz, J. (1999). Interest rates, risk, and imperfect markets: puzzles and policies, Oxford Review of Economic Policy 15(2): 59-76.

Taylor, J. B. (1995). The monetary transmission mechanism: An empirical framework, Journal of Economic Perspectives 9(4): 11-26.

Thorbecke, W. (1997). On stock market returns and monetary policy, Journal of Finance 52(2): 635-54.

Tobin, J. (1969). A general equilibrium approach to monetary theory, Journal of Money, Credit and Banking 1(1): pp. 15-29.

Uhlig, H. (2005). What are the effects of monetary policy on output? results from an agnostic identification procedure, Journal of Monetary Economics 52(2): 381-419.

Vickers, J. (2000). Monetary policy and asset prices, The Manchester School 68: 1-22. 


\section{Appendix}

Figure 3: Responses to monetary policy shock using Cholesky orderings.
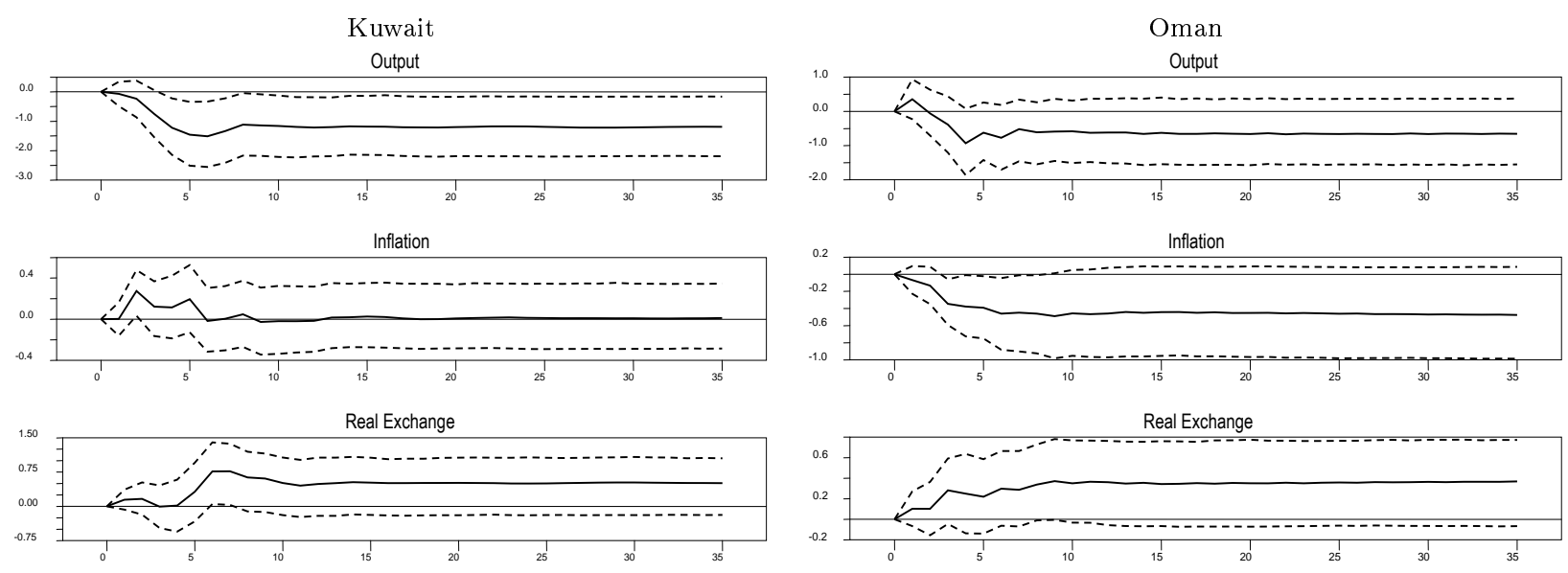

Saudi Arabia
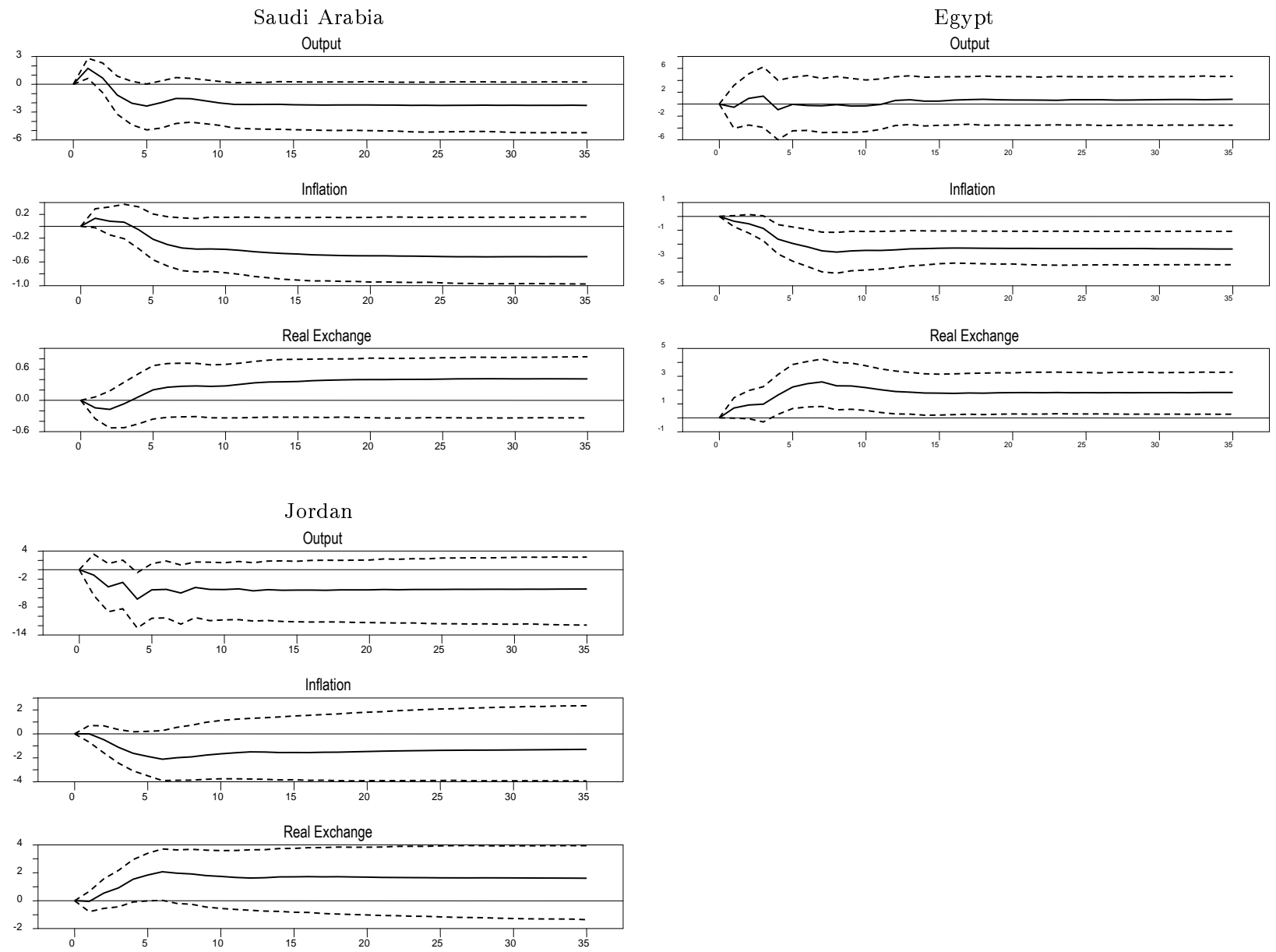

The probability bands are obtained using the method of Monte Carlo integration as in Doan (2010) with 2000 draws. 
Figure 4: Response to monetary policy shock with long run restrictions.

Kuwait
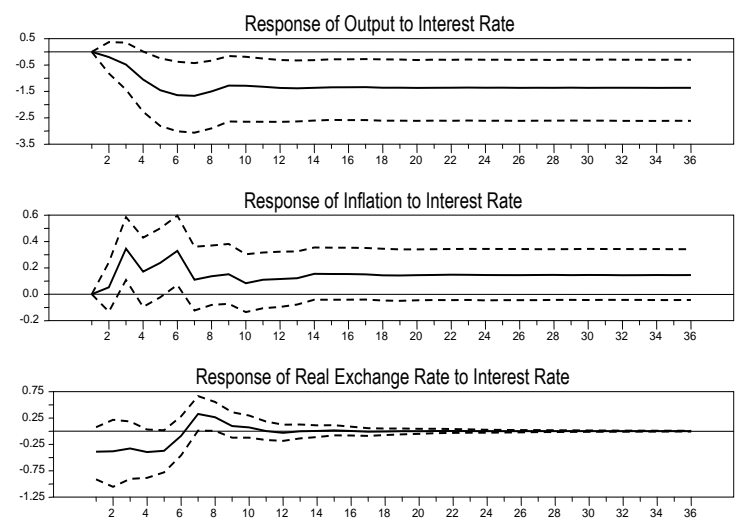

Saudi Arabia
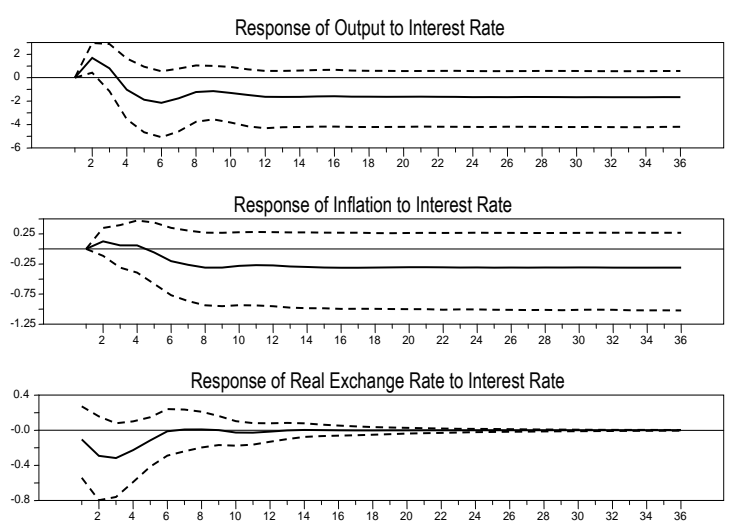

Jordan
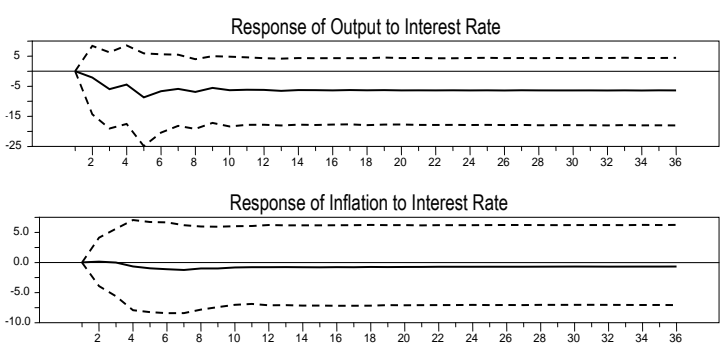

Response of Real Exchange Rate to Interest Rate

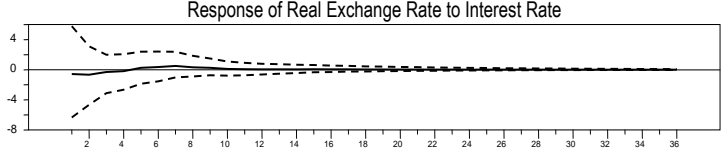

Oman

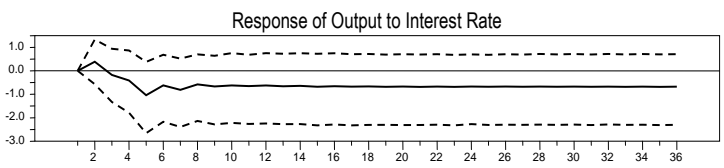

Response of Inflation to Interest Rate
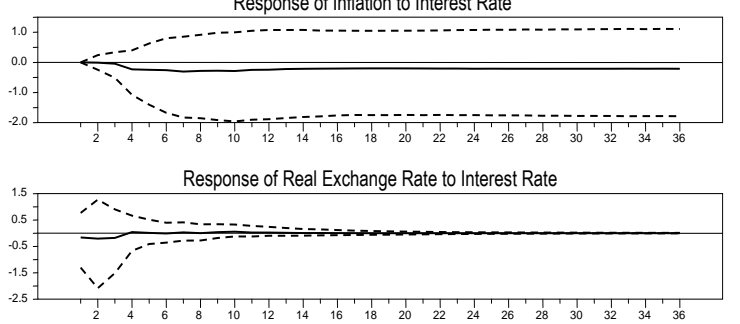

Egypt
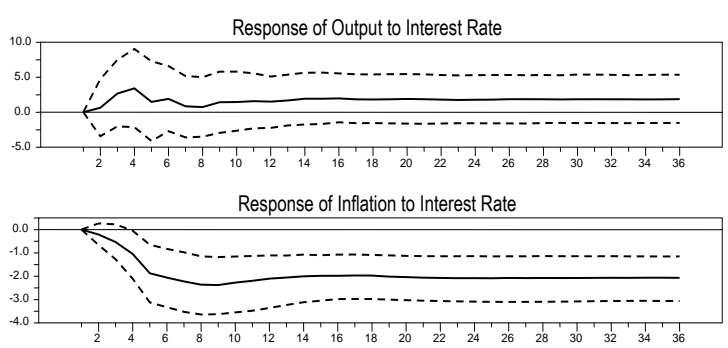

Response of Real Exchange Rate to Interest Rate

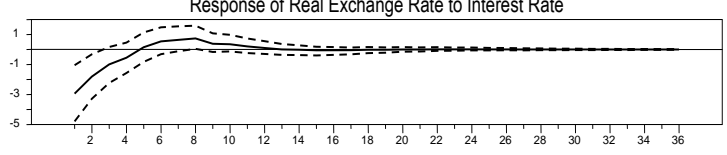

The probability bands are obtained using the method of Monte Carlo integration as in Doan (2010) with 10000 draws. 
Figure 5: Response to exchange rate shock with long run restrictions.

Kuwait

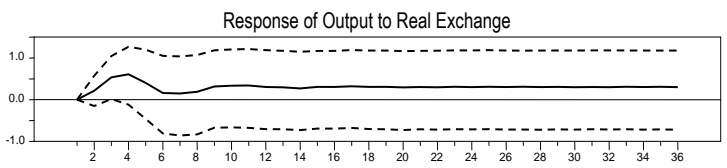

Response of Inflation to Real Exchange

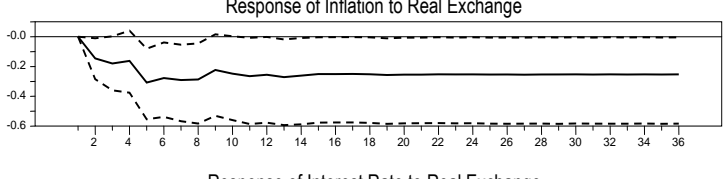

Response of Interest Rate to Real Exchange

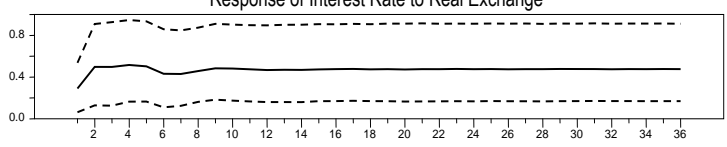

Saudi Arabia

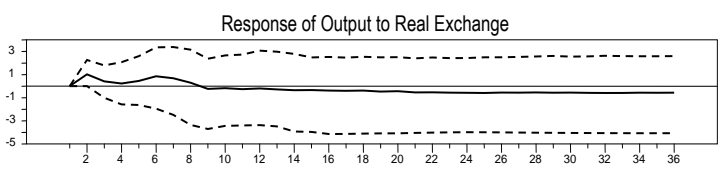

Response of Inflation to Real Exchange

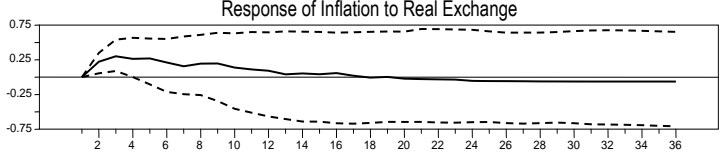

Response of Interest Rate to Real Exchange

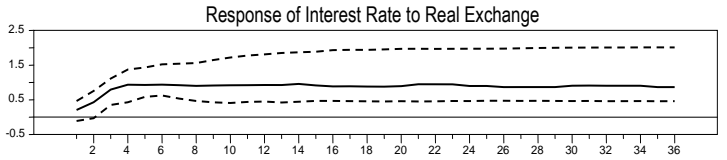

Jordan

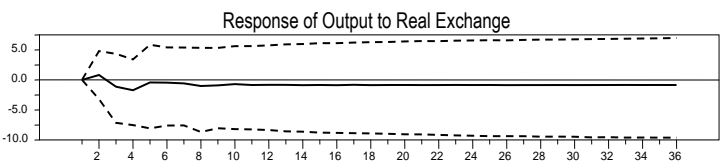

Response of Inflation to Real Exchange

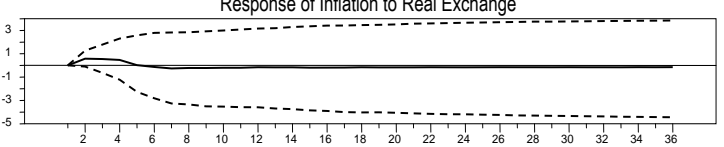

Response of Interest Rate to Real Exchang

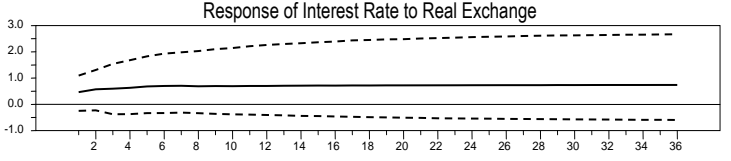

Oman

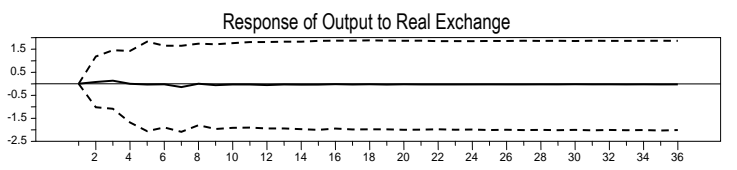

Response of Inflation to Real Exchange

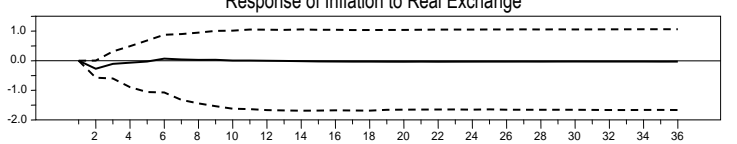

Response of Interest Rate to Real Exchange

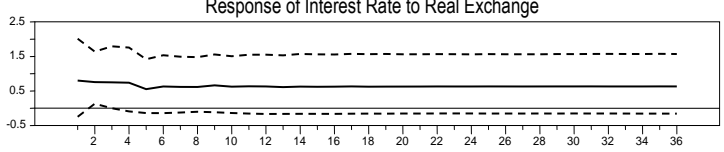

Egypt

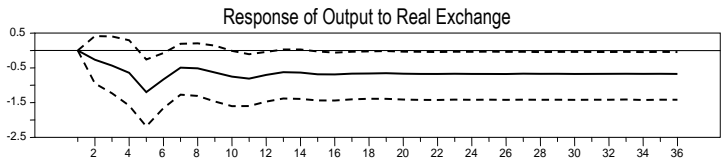

Response of Inflation to Real Exchange
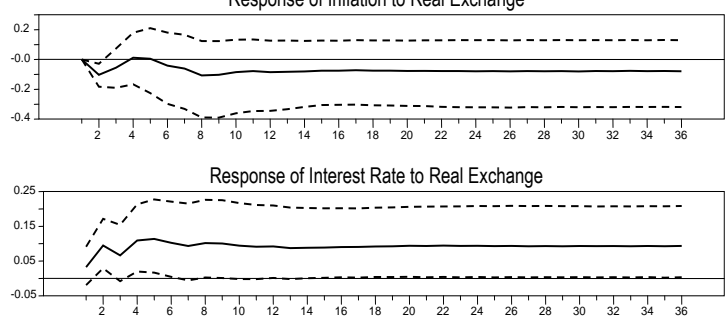

The probability bands are obtained using the method of Monte Carlo integration as in Doan (2010) with 10000 draws. 
Figure 6: Response to Stock Price Shock with Long Run Restrictions.

Kuwait
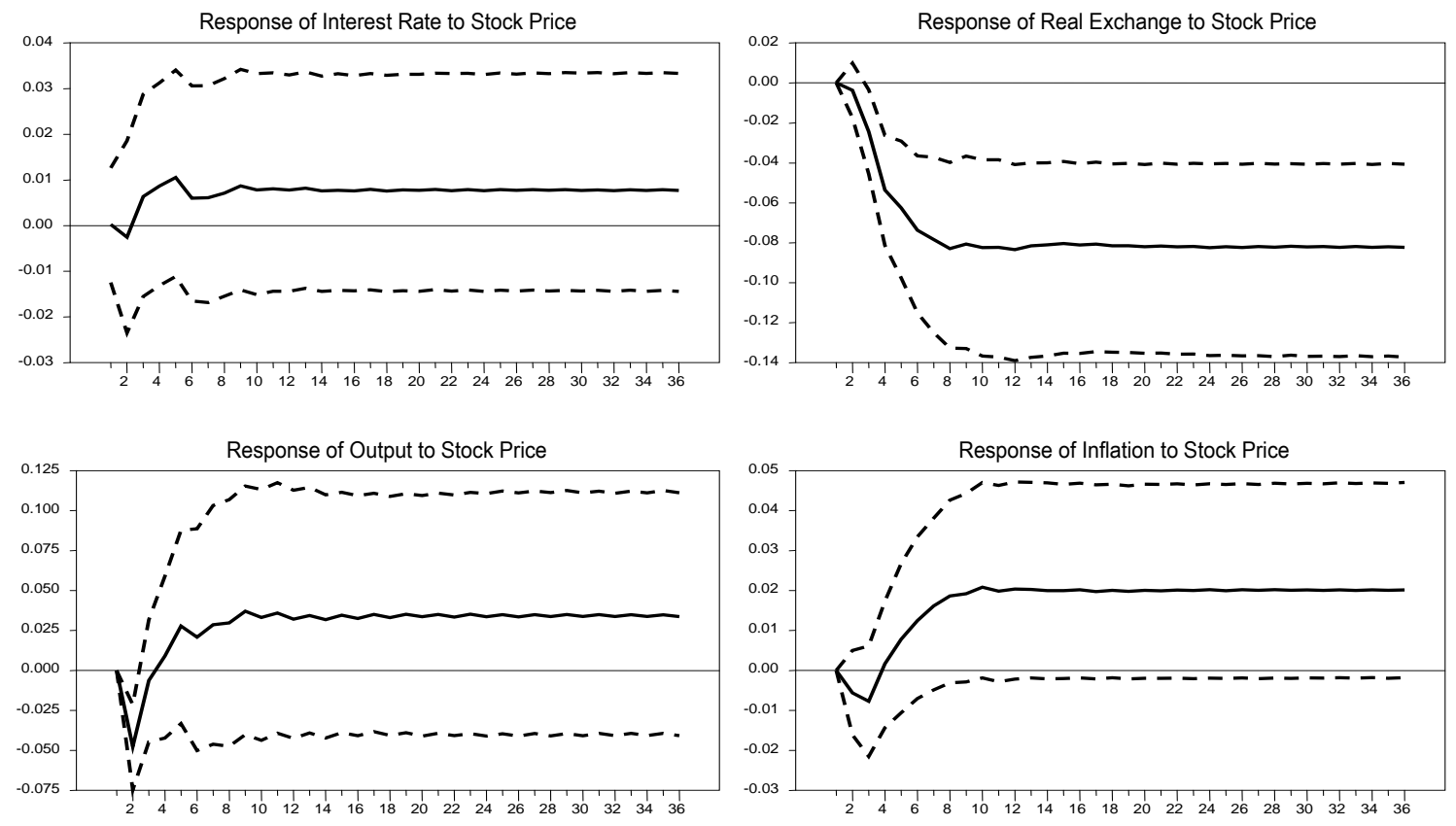

Oman
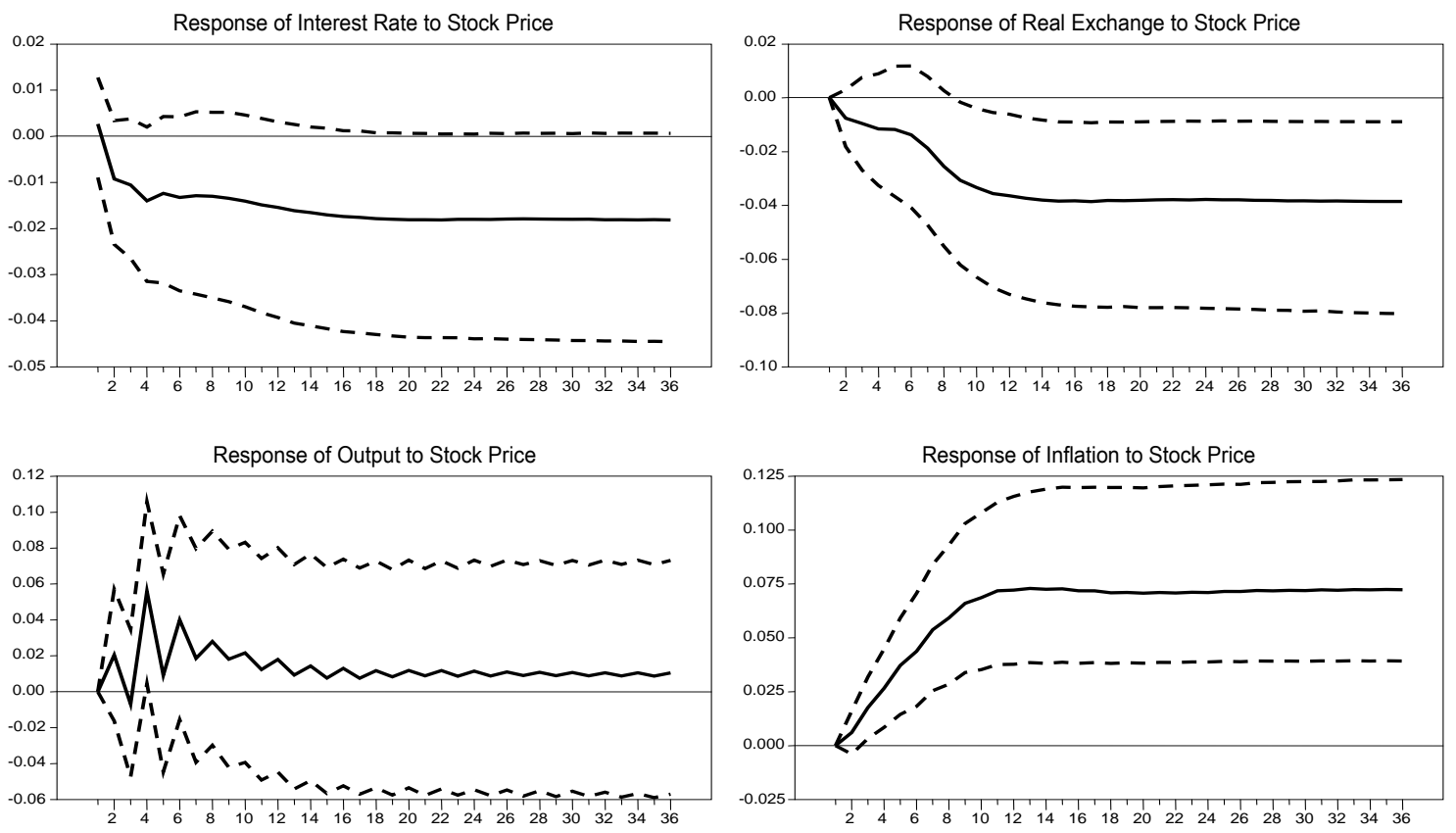

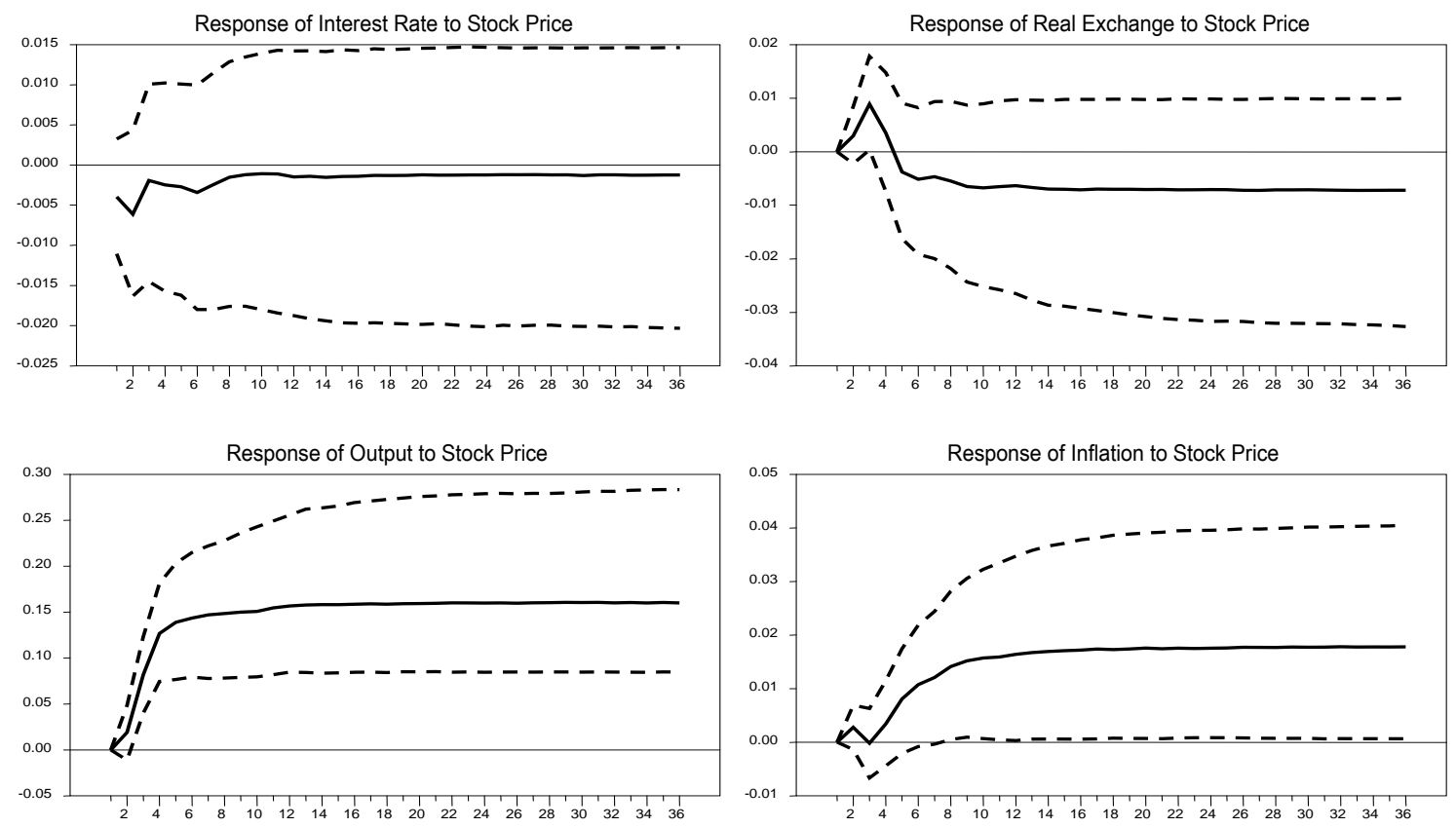

Egypt
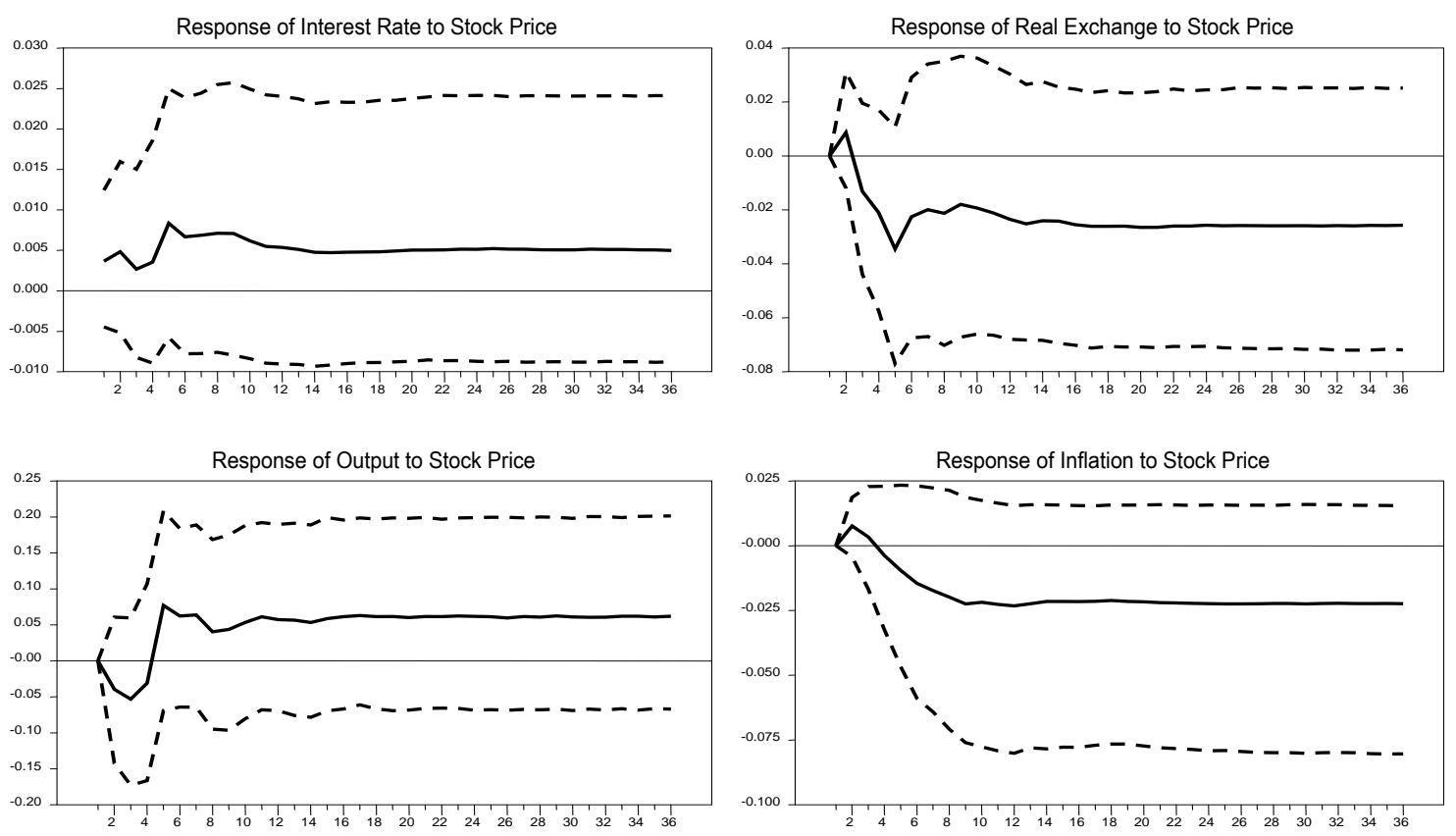
Jordan
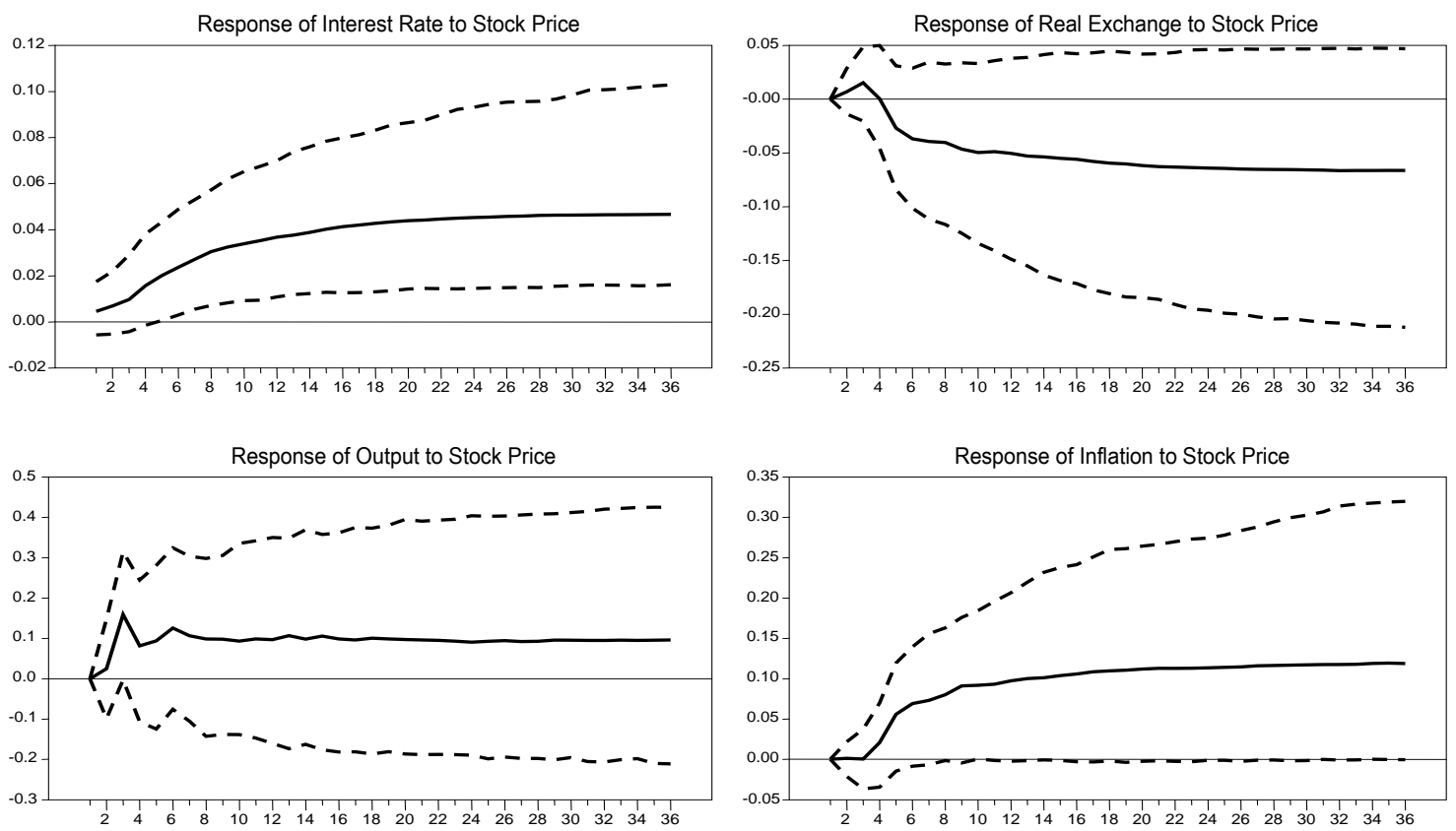

The probability bands are obtained using the method of Monte Carlo integration as in Doan (2010) with 10000 draws. 